\title{
Evidence of Facilitated Transport in Crowded Nanopores
}

\author{
Anh Phan* and Alberto Striolo*
}

Cite This: J. Phys. Chem. Lett. 2020, 11, 1814-1821

Read Online

ABSTRACT: Fluid transport in nature often occurs through crowded nanopores, where a number of phenomena can affect it, because of fluid-fluid and fluid-solid interactions, as well as the presence of organic compounds filling the pores and their structural fluctuations. Employing molecular dynamics, we probe here the transport of fluid mixtures $\left(\mathrm{CO}_{2}-\mathrm{CH}_{4}\right.$ and $\mathrm{H}_{2} \mathrm{~S}-\mathrm{CH}_{4}$ ) through silica nanopores filled with benzene. Both $\mathrm{CO}_{2}$ and $\mathrm{H}_{2} \mathrm{~S}$ are strongly adsorbed within the organic-filled pore, partially displacing benzene. Unexpectedly, $\mathrm{CO}_{2} / \mathrm{H}_{2} \mathrm{~S}$ adsorption facilitates $\mathrm{CH}_{4}$ transport. Analysis of the trajectories suggests that both $\mathrm{CO}_{2}$ and $\mathrm{H}_{2} \mathrm{~S}$ act as vehicle-like carriers and might swell benzene, generating preferential transport pathways within the crowded pore. The results are useful for identifying unexpected transport mechanisms and for developing engineering approaches that could lead to storage of $\mathrm{CO}_{2}$ in caprocks.

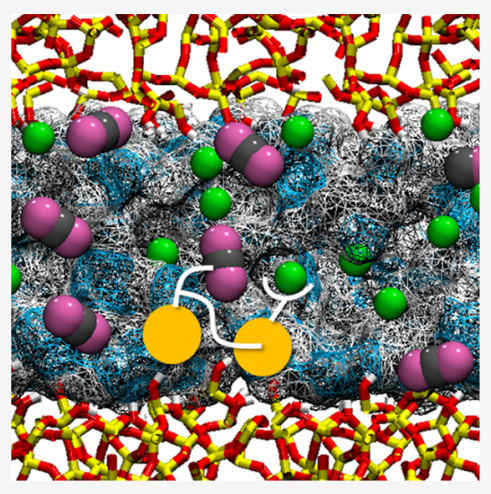

$\mathrm{C}$ arbon dioxide $\left(\mathrm{CO}_{2}\right)$ injection in geologic reservoirs could provide one solution for carbon capture and storage (CCS) ${ }^{1-3}$ Fine-grained sedimentary rocks (shales and mudstone) can provide caprocks in CCS sites. ${ }^{4,5}$ These rocks also play important roles in shale gas production. ${ }^{6}$ As-produced shale gas from Haynesville and Barnett shales in the United States and Horn River in western Canada contains various amounts of $\mathrm{CO}_{2}{ }^{7-11}$ and up to several hundred parts per million of hydrogen sulfide $\left(\mathrm{H}_{2} \mathrm{~S}\right)$, even in sites in which $\mathrm{H}_{2} \mathrm{~S}$ was absent in initial assessments. ${ }^{12}$ The produced gas is "sweetened" ${ }^{8,10}$ to avoid harmful effects on health, safety, and the environment. ${ }^{13}$ In some cases, it might be attractive to reinject both $\mathrm{H}_{2} \mathrm{~S}$ and $\mathrm{CO}_{2}$ into the formation. ${ }^{14}$

A comprehensive understanding of the fundamental mechanisms responsible for carbon bearing-fluid migration in the presence of $\mathrm{CO}_{2} / \mathrm{H}_{2} \mathrm{~S}$ is crucial for risk assessment and site selection for geologic CCS, monitoring $\mathrm{H}_{2} \mathrm{~S}$ emissions, and perhaps identifying innovative enhanced oil recovery (EOR) processes that use $\mathrm{CO}_{2}$ and $\mathrm{H}_{2} \mathrm{~S} .{ }^{15,16}$ Because a thorough quantification of the phenomena that govern fluid transport in the complex heterogeneous pore networks found in organic-rich shale caprocks, which consist of crowded nanopores that provide poor connections between dispersed pockets of organic matter, remains elusive, because of practical difficulties in observing fluid transport in such complicated systems, computational approaches could be helpful. ${ }^{17-20}$

This study probes transport of systems containing $\mathrm{CO}_{2}, \mathrm{H}_{2} \mathrm{~S}$, and methane $\left(\mathrm{CH}_{4}\right)$, through a realistic $\sim 2 \mathrm{~nm}$ amorphous silica nanopore saturated with benzene molecules, a model to mimic organic-rich shale caprocks. The number of benzene molecules introduced in the system (400) was sufficient to fill the pore volume and form thin layers on the solid substrate outside the pore (see Figure S1 of the Supporting Information, panel A).
The transport results are complemented by careful analysis of mutual solubility, free-energy profiles, and structure of the confined systems. Atomistic molecular dynamics (MD) simulations are conducted at geological temperature $(300 \mathrm{~K})$ and pressure $(\sim 13.9 \mathrm{MPa})$ conditions. $^{21,22}$ Various system compositions in the bulk reservoirs are considered, as shown in Figure S1, panel B. Once equilibrium was achieved, system properties such as density profiles for $\mathrm{CO}_{2}, \mathrm{H}_{2} \mathrm{~S}, \mathrm{CH}_{4}$, and benzene molecules were determined within the pore as well as in the bulk reservoirs (see Table 1). Details regarding simulation models, algorithms, methods, and computational procedures are reported in the Supporting Information.

We calculated the solubility of $\mathrm{CO}_{2}, \mathrm{H}_{2} \mathrm{~S}$, and $\mathrm{CH}_{4}$ in confined benzene as a function of system composition. The results (Figure $1 \mathrm{~A}$, left panel) suggest that $\mathrm{CO}_{2}$ and $\mathrm{H}_{2} \mathrm{~S}$ solubility increase linearly when the respective bulk mole fractions increase to 0.21 and $0.12 . \mathrm{H}_{2} \mathrm{~S}$ (yellow) is more soluble in confined benzene than $\mathrm{CO}_{2}$ (blue), achieving a solubility coefficient of $7.26\left(0.33 \mathrm{MPa}^{-1}\right)$ compared to 2.38 (0.13 $\mathrm{MPa}^{-1}$ ) for $\mathrm{CO}_{2}$. For comparison, $\mathrm{H}_{2} \mathrm{~S}$ is more soluble in bulk benzene than $\mathrm{CO}_{2}$, with experimental solubility coefficients being $0.56 \mathrm{MPa}^{-1}$ for $\mathrm{H}_{2} \mathrm{~S}$ and $0.15 \mathrm{MPa}^{-1}$ for $\mathrm{CO}_{2}$ at $\sim 300$ $\mathrm{K} .{ }^{23,24}$ Because bulk simulations overestimate the experimental solubility, the results in Figure 1A suggest that confinement strongly reduces the solubility of $\mathrm{H}_{2} \mathrm{~S}$ and $\mathrm{CO}_{2}$ in benzene, which is contrary to many results for other confined systems, in which confinement increases solubility. ${ }^{25,26}$ It is possible that

Received: December 17, 2019

Accepted: January 24, 2020

Published: January 24, 2020 
Table 1. Mole Fraction of $\mathrm{CH}_{4}, \mathrm{CO}_{2}$, and $\mathrm{H}_{2} \mathrm{~S}$ in the Bulk Reservoirs as Well as Number of $\mathrm{CH}_{4}, \mathrm{CO}_{2}, \mathrm{H}_{2} \mathrm{~S}$, and Benzene Molecules Confined in the Pore for All Systems Simulated after Equilibration Was Achieved

\begin{tabular}{cllrrrr} 
& \multicolumn{2}{c}{ bulk reservoirs } & & \multicolumn{3}{c}{ pore } \\
\cline { 2 - 3 } \cline { 5 - 6 } system & $x_{\mathrm{CO}_{2}}$ & $x_{\mathrm{CH}_{4}}$ & & $n_{\mathrm{CO}_{2}}$ & $n_{\mathrm{CH}_{4}}$ & $n_{\mathrm{C}_{6} \mathrm{H}_{6}}$ \\
\hline 0 & 0.0 & 1.0 & & 0 & 97 & 236 \\
$1 \mathrm{C}$ & 0.03 & 0.97 & & 13 & 98 & 231 \\
$2 \mathrm{C}$ & 0.05 & 0.95 & & 28 & 96 & 227 \\
$3 \mathrm{C}$ & 0.10 & 0.90 & & 51 & 88 & 220 \\
$4 \mathrm{C}$ & 0.21 & 0.79 & & 102 & 77 & 204 \\
$5 \mathrm{C}$ & 0.27 & 0.73 & & 122 & 78 & 192 \\
$6 \mathrm{C}$ & 0.30 & 0.70 & & 151 & 72 & 184 \\
$7 \mathrm{C}$ & 0.34 & 0.66 & & 167 & 71 & 176 \\
$8 \mathrm{C}$ & 0.40 & 0.60 & & 183 & 64 & 175 \\
& $x_{\mathrm{H}_{2} \mathrm{~S}}$ & $x_{\mathrm{CH}}$ & & $n_{\mathrm{H}_{2} \mathrm{~S}}$ & $n_{\mathrm{CH}}$ & $n_{\mathrm{C}_{6} \mathrm{H}_{6}}$ \\
$1 \mathrm{H}$ & 0.02 & 0.98 & & 21 & 100 & 227 \\
$2 \mathrm{H}$ & 0.03 & 0.97 & & 43 & 95 & 221 \\
$3 \mathrm{H}$ & 0.06 & 0.94 & & 80 & 89 & 208 \\
$4 \mathrm{H}$ & 0.12 & 0.88 & 152 & 83 & 180 \\
$5 \mathrm{H}$ & 0.15 & 0.85 & 170 & 84 & 172 \\
$6 \mathrm{H}$ & 0.19 & 0.81 & 196 & 80 & 160 \\
$7 \mathrm{H}$ & 0.21 & 0.79 & 220 & 79 & 152 \\
\hline & & & & & & \\
\hline
\end{tabular}

confined benzene cannot solvate $\mathrm{CO}_{2}$ and $\mathrm{H}_{2} \mathrm{~S}$ molecules as effectively as it does in the bulk, a mechanism similar to the one invoked to explain the lower $\mathrm{H}_{2} \mathrm{~S}$ solubility in confined water. ${ }^{27}$

Our results show that loading $\mathrm{H}_{2} \mathrm{~S}$ into the benzene-filled $\mathrm{SiO}_{2}$ pore enhances the solubility of $\mathrm{CH}_{4}$ in the same pore, while adding $\mathrm{CO}_{2}$ reduces $\mathrm{CH}_{4}$ solubility (Figure $1 \mathrm{~A}$, right panel). This observation could have ramifications for improving shale gas extraction. Our simulations also suggest that $\mathrm{CH}_{4}$ is less strongly adsorbed in the $\mathrm{SiO}_{2}$ pore filled with benzene compared to $\mathrm{H}_{2} \mathrm{~S}$ and $\mathrm{CO}_{2}$ (see Figure S2).

The amount of benzene confined in the nanopore decreases as the bulk mole faction of $\mathrm{CO}_{2}$ (blue) and $\mathrm{H}_{2} \mathrm{~S}$ (yellow) increases (Figure 1B). In particular, our analysis suggests that $10 \mathrm{H}_{2} \mathrm{~S}$ molecules displace $4 \mathrm{C}_{6} \mathrm{H}_{6}$ molecules from the pore, while 10 $\mathrm{CO}_{2}$ molecules displace $3 \mathrm{C}_{6} \mathrm{H}_{6}$ molecules (see Figure $\mathrm{S} 3$ ). These results suggest that varying the minority fluids mixed with $\mathrm{CH}_{4}$ strongly affects the structure of organics trapped in caprock nanopores and might also be responsible for the pronounced differences observed for $\mathrm{CH}_{4}$ solubility in confined benzene (Figure 1A, right panel).

To assess whether the results shown in Figure 1A,B are representative of equilibrated systems, we carried out adsorption-desorption cycles. By employing the "evaporate" and "deposit" procedures available in the software package, ${ }^{28}$ we extracted $\mathrm{CO}_{2} / \mathrm{H}_{2} \mathrm{~S}$ molecules and simultaneously inserted $\mathrm{CH}_{4}$ molecules into the simulated systems. The results in Figure 1A,B show negligible adsorption-desorption hysteresis, suggesting that all simulated processes are reversible and that the results represent equilibrated systems. The results show (Figure 1B) that reducing the bulk $\mathrm{CO}_{2} / \mathrm{H}_{2} \mathrm{~S}$ mole fraction prompts benzene readsorption into the $\mathrm{SiO}_{2}$ nanopore.

To document the molecular structure of benzene inside the crowded pore, we calculated in-plane surface density distributions of benzene carbon atoms within layers parallel to the pore surfaces. The results for $\mathrm{CO}_{2}-\mathrm{CH}_{4}$ (left) and $\mathrm{H}_{2} \mathrm{~S}-\mathrm{CH}_{4}$ (right) mixtures are shown in Figure 1C. Details regarding the layer positions are presented in Figure S4. The first and fourth layers are near the bottom and top silica surfaces, respectively, while the second and third layers are approximately in the middle of the pore. The high-density areas (red-yellow spots) of the contour plots indicate positions where the benzene molecules preferentially reside. The results strongly suggest that the distributions of benzene molecules in the first and fourth layers are not altered by the presence of $\mathrm{CO}_{2}$ and $\mathrm{H}_{2} \mathrm{~S}$, indicating that the adsorbed $\mathrm{CO}_{2} / \mathrm{H}_{2} \mathrm{~S}$ molecules are not able to displace the benzene molecules adsorbed on the pore surfaces. Rather, they displace the benzene molecules accumulated in the middle of the pore, with the result that the distribution of corresponding benzene molecules changes significantly as the $\mathrm{CO}_{2} / \mathrm{H}_{2} \mathrm{~S}$ bulk mole fraction increases. The density profiles suggest that $\mathrm{H}_{2} \mathrm{~S}$ displaces more benzene than $\mathrm{CO}_{2}$ does, which is consistent with the results of Figure 1B. We conducted additional simulations for some systems in which the $\mathrm{SiO}_{2}$ pore was initially exposed to $\mathrm{CO}_{2} / \mathrm{H}_{2} \mathrm{~S}$ and subsequently to benzene. The results for the distributions of benzene molecules near the silica surfaces were similar to those shown in Figure 1C, which suggests preferential adsorption of benzene on silica for the systems considered here.

To understand the results shown in Figure 1, we calculated the adsorption energy of benzene, $\mathrm{CH}_{4}, \mathrm{CO}_{2}$, and $\mathrm{H}_{2} \mathrm{~S}$ in the nanopore filled with benzene and $\mathrm{CH}_{4}$ (system 0 in Table 1 and Figure S1) using the two-box approach proposed by Heinz. ${ }^{29}$ This method involves the simulation of the adsorbate within the pore and in bulk (Figure 2A). The results in Figure 2B show that $\mathrm{H}_{2} \mathrm{~S}$ is more strongly adsorbed than the other species, achieving an adsorption energy of $-2.13 \mathrm{eV}$. To compare the values in Figure 2, we refer to ab initio studies of $\mathrm{H}_{2} \mathrm{~S}$-benzene, $\mathrm{CO}_{2}-$ benzene, $\mathrm{CH}_{4}$-benzene, and benzene-benzene dimers. ${ }^{30-33}$ The corresponding interaction energies are approximately $-2.83,-2.55,-1.47$, and -1.81 to $-2.78 \mathrm{kcal} / \mathrm{mol}$, respectively. ${ }^{30-33}$ The results in Figure 2 explain why benzene is displaced more effectively by $\mathrm{H}_{2} \mathrm{~S}$ than by $\mathrm{CO}_{2}$. The interaction energies for benzene-benzene dimers with the $\mathrm{T}$ shaped and parallel-displaced configurations are -2.74 and $-2.78 \mathrm{kcal} / \mathrm{mol},{ }^{32}$ both stronger than that reported for $\mathrm{CO}_{2}-$ benzene dimers $(-2.55 \mathrm{kcal} / \mathrm{mol}){ }^{30}$ the highly positive adsorption energy calculated here $(0.44 \mathrm{eV}$, see Figure $2 \mathrm{~B})$ suggests that benzene is unlikely to be adsorbed in the nanopore considered, probably because the pore is already filled.

A pressure gradient is imposed through the benzene-filled nanopore via implementing boundary driven nonequilibrium simulations (see Figure S5). As a function of the pressure gradient, a molecular flux is established. Once the steady-state flow is achieved, we extracted molar fluxes, permeability, and transport diffusivity $\left(D_{t}\right)$. The latter is quantified in the limit of the external force approaching zero, when the structure of the benzene-filled pore should remain unchanged in response to the applied pressure. This is confirmed via in-plane density distributions at equilibrium and during flow (Figure S6).

In Figure 3A, the permeabilities are shown for $\mathrm{CO}_{2}$ and $\mathrm{H}_{2} \mathrm{~S}$ (left panel, blue and yellow, respectively) as well as $\mathrm{CH}_{4}$ mixed with $\mathrm{CO}_{2} / \mathrm{H}_{2} \mathrm{~S}$ (right panel, blue/yellow) as a function of system composition. We considered only those systems with $\mathrm{CO}_{2}$ $\left(/ \mathrm{H}_{2} \mathrm{~S}\right)$ mole fraction $<0.21(/ 0.12)$ as these exhibit linear changes in the adsorption isotherms (see Figure 1A) and because the $\mathrm{CH}_{4}$ mole fraction in shale gas is typically $>0.8$. ${ }^{34,35}$ The results in Figure $3 \mathrm{~A}$ show that $\mathrm{H}_{2} \mathrm{~S}$ permeates the pore much faster than $\mathrm{CO}_{2}$ and $\mathrm{CH}_{4}$. Increasing both $\mathrm{CO}_{2}$ and $\mathrm{H}_{2} \mathrm{~S}$ bulk mole fraction enhances the permeability of all species, probably because $\mathrm{CO}_{2}$ and $\mathrm{H}_{2} \mathrm{~S}$ displace benzene from the pore, opening preferential pathways across the crowded nanopore. 

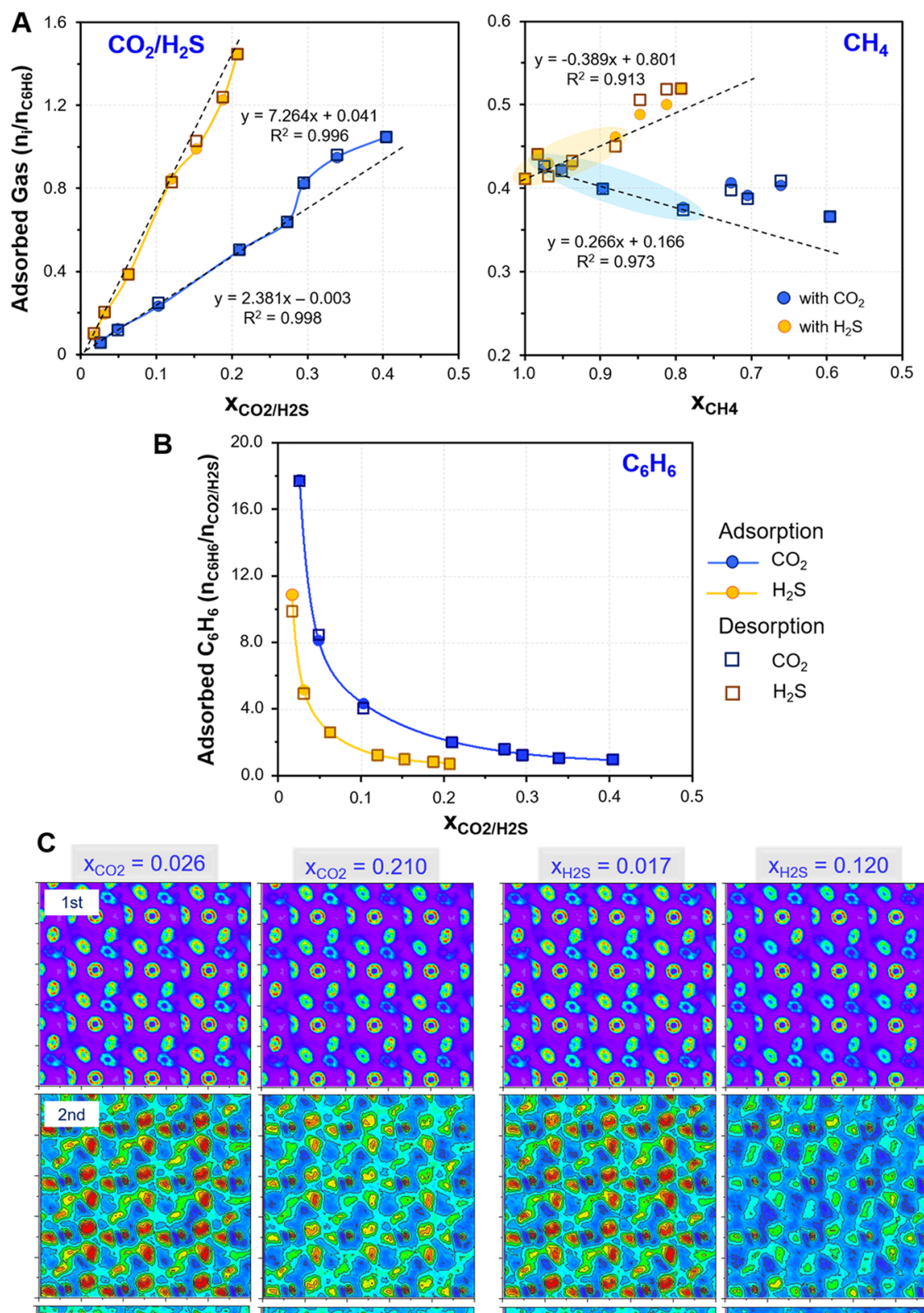

Adsorption

$\rightarrow \mathrm{CO}_{2}$

$-\mathrm{H}_{2} \mathrm{~S}$

Desorption

$\square \quad \mathrm{CO}_{2}$

$\square \quad \mathrm{H}_{2} \mathrm{~S}$
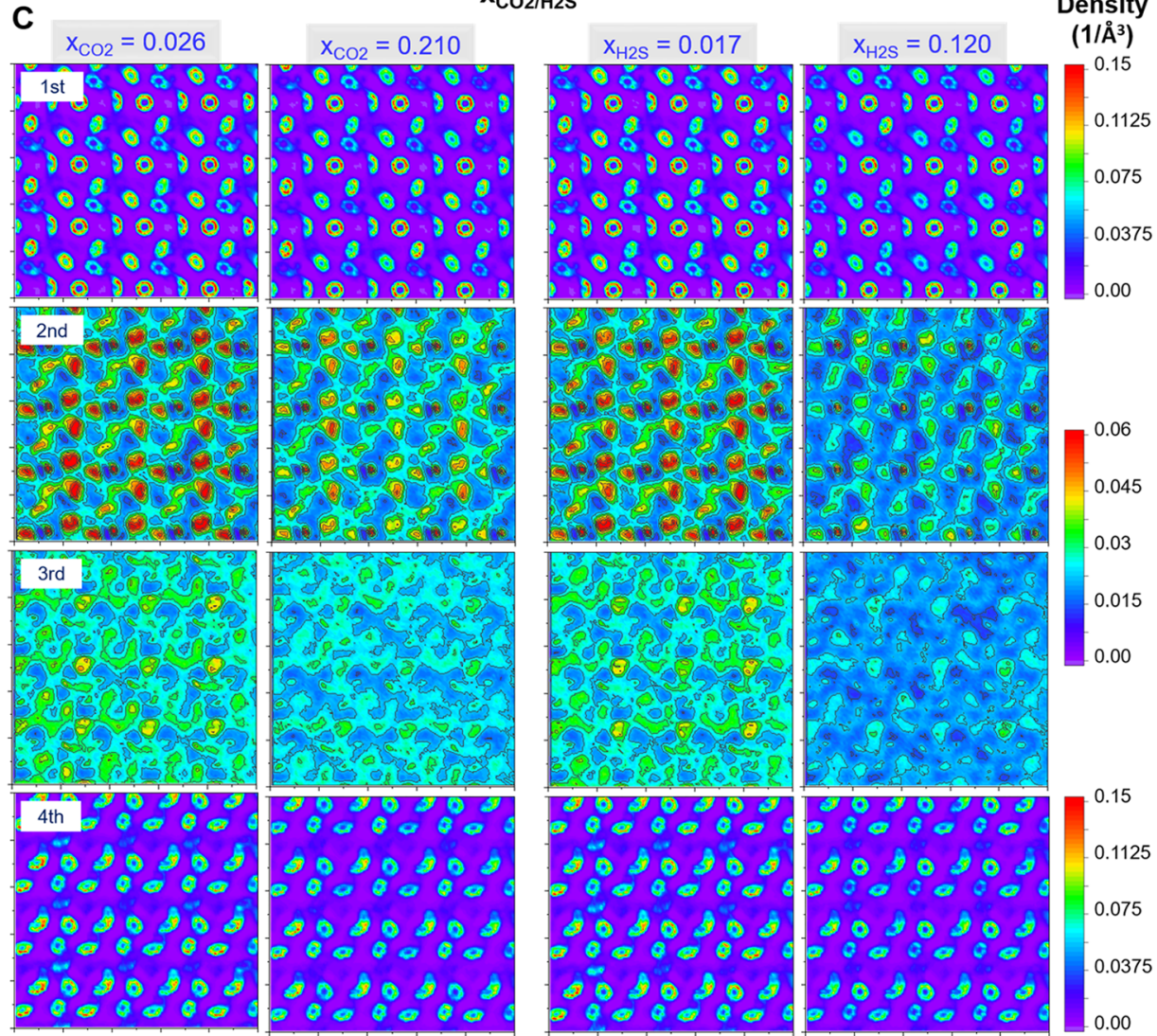

Figure 1. (A) Solubility of $\mathrm{CO}_{2} / \mathrm{H}_{2} \mathrm{~S}$ (blue/yellow, left panel) and $\mathrm{CH}_{4}$ (blue/yellow, right panel) inside the benzene-filled pore at $300 \mathrm{~K}$ as a function of $\mathrm{CO}_{2} / \mathrm{H}_{2} \mathrm{~S}$ and $\mathrm{CH}_{4}$ mole fractions, respectively, in the bulk reservoirs. (B) Amount of confined benzene per adsorbed $\mathrm{CO}_{2} / \mathrm{H}_{2} \mathrm{~S}$ molecule as a function of $\mathrm{CO}_{2}$ (blue) and $\mathrm{H}_{2} \mathrm{~S}$ (yellow) bulk mole fractions. Closed and open symbols represent data obtained during adsorption and desorption of $\mathrm{CO}_{2} / \mathrm{H}_{2} \mathrm{~S}$, respectively. (C) In-plane surface density distributions of benzene molecules within first, second, third, and fourth layers formed within the amorphous silica pore. Results are obtained for $\mathrm{CO}_{2}-\mathrm{CH}_{4}$ (left) and $\mathrm{H}_{2} \mathrm{~S}-\mathrm{CH}_{4}$ (right) mixtures at various $\mathrm{CO}_{2} / \mathrm{H}_{2} \mathrm{~S}$ bulk mole fractions, as indicated above the panels. Details on computational procedures are available in the Supporting Information. 

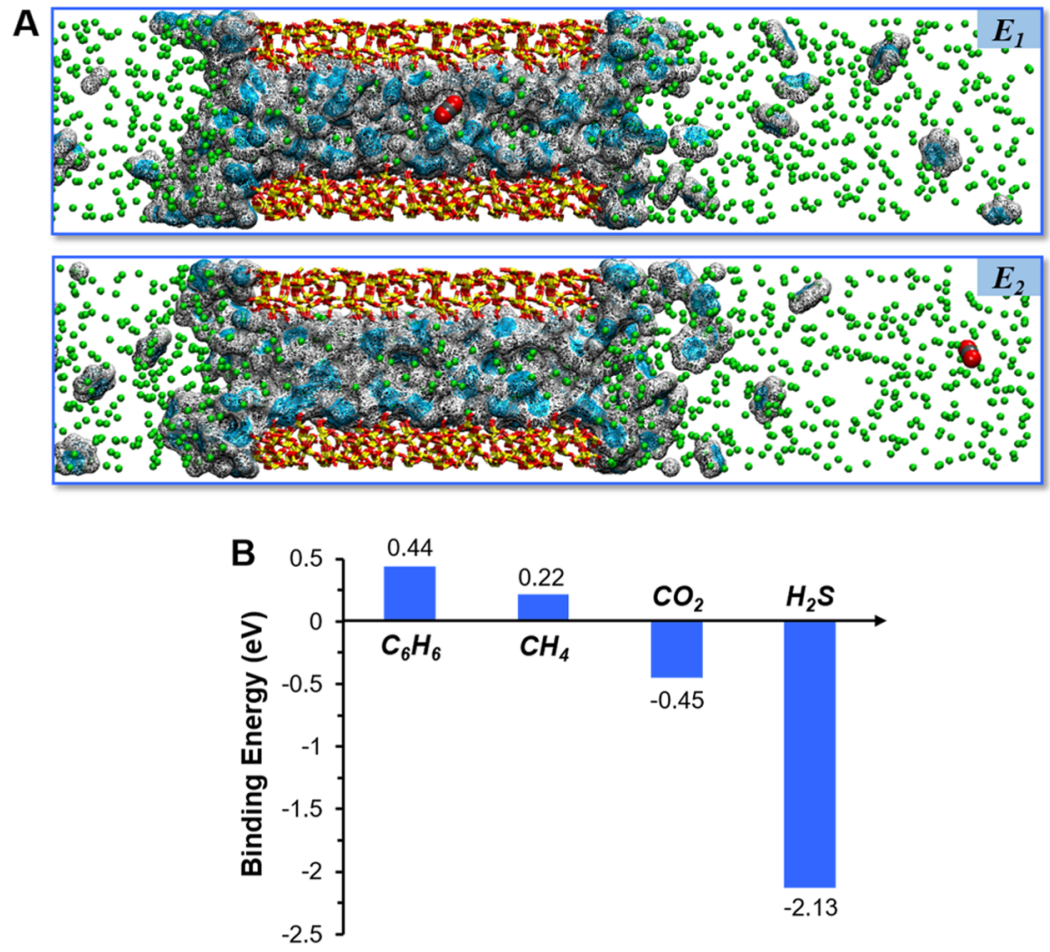

Figure 2. (A) Representative simulation snapshots for the calculation of average energies (one benzene, $\mathrm{CH}_{4}, \mathrm{CO}_{2}$, and $\mathrm{H}_{2} \mathrm{~S}$ molecule) within the $\mathrm{SiO}_{2}$ pore filled with benzene and $\mathrm{CH}_{4}$ (top) and in the bulk reservoirs containing only $\mathrm{CH}_{4}$ (bottom) at $300 \mathrm{~K}$. (B) Adsorption energies of benzene, $\mathrm{CH}_{4}$, $\mathrm{CO}_{2}$, and $\mathrm{H}_{2} \mathrm{~S}$ in the pore filled with benzene and $\mathrm{CH}_{4}$.

The permeability of $\mathrm{CO}_{2}, \mathrm{H}_{2} \mathrm{~S}$, and $\mathrm{CH}_{4}$ depends linearly on $\mathrm{CO}_{2} / \mathrm{H}_{2} \mathrm{~S}$ bulk concentrations. Notably, the results show a decline in the rates of permeability increase for $\mathrm{CH}_{4}$ mixed with $\mathrm{CO}_{2}$ at $\mathrm{CO}_{2}$ bulk mole fractions $>0.05$. The permeability of $\mathrm{CH}_{4}$ mixed with $\mathrm{H}_{2} \mathrm{~S}$ is greater than that of $\mathrm{CH}_{4}$ mixed with $\mathrm{CO}_{2}$ at $x_{\mathrm{CO}_{2} / \mathrm{H}_{2} \mathrm{~S}}>0.05$, indicating that ultilizing $\mathrm{H}_{2} \mathrm{~S}$ could be advantageous for improving shale gas extraction.

The transport diffusivity for the various gases can be extracted by dividing the permeability by the solubility within the nanopore. ${ }^{36}$ We report solubility data for each species in Table S1. In interpeting those results, it should be noted that, as the bulk mole fraction of $\mathrm{CH}_{4}$ decreases, the amount of benzene in the pore also decreases (see Figure 1B). We also computed the self-diffusivity for the various species inside the crowded pore using the Green-Kubo formulation. ${ }^{37}$

In Figure 3B, we present transport- (closed circles) and self(open squares) diffusivity for $\mathrm{CO}_{2}$ and $\mathrm{H}_{2} \mathrm{~S}$ (left panel, blue and yellow, respectively) and for $\mathrm{CH}_{4}$ (right panel) for the various systems simulated. Similar to the permeability results, we observe a linear relation between transport (/self) diffusivities of $\mathrm{CO}_{2} / \mathrm{H}_{2} \mathrm{~S}$ and the corresponding bulk mole fractions. However, the transport (/self) diffusivity of $\mathrm{CH}_{4}$ first decreases upon loading $\mathrm{CO}_{2} / \mathrm{H}_{2} \mathrm{~S}$, and then increases. The results show that $\mathrm{CH}_{4}$ diffuses faster than $\mathrm{CO}_{2}$ and $\mathrm{H}_{2} \mathrm{~S}$, achieving transport (/self) diffusivity of $\sim 2.4 \div 6.8 \times 10^{-9} \mathrm{~m}^{2} / \mathrm{s}$, as opposed to $\sim 2.25 \div 3.5 \times 10^{-9} \mathrm{~m}^{2} / \mathrm{s}$ for $\mathrm{CO}_{2}$ and $\mathrm{H}_{2} \mathrm{~S}$ when the $\mathrm{CO}_{2}$ $\left(/ \mathrm{H}_{2} \mathrm{~S}\right)$ mole fraction is $<0.21(/ 0.12)$. This is probably a consequence of the weaker attraction between $\mathrm{CH}_{4}$ and the benzene-filled pore (see Figure 2). In contrast, although $\mathrm{H}_{2} \mathrm{~S}$ is more strongly adsorbed inside the pore than $\mathrm{CO}_{2}$, it moves faster than $\mathrm{CO}_{2}$, possibly because $\mathrm{H}_{2} \mathrm{~S}$ displaces more benzene from the pore than $\mathrm{CO}_{2}$ does (see Figure 1B). At infinitely diluted conditions $\left(x_{\mathrm{CO}_{2} / \mathrm{H}_{2} \mathrm{~S}} \rightarrow 0\right)$, the transport diffusivity of $\mathrm{CO}_{2}$ and that of $\mathrm{H}_{2} \mathrm{~S}$ are similar $\left(\sim 2.3 \times 10^{-9} \mathrm{~m}^{2} / \mathrm{s}\right)$. Recently, An et al..$^{38}$ conducted nuclear magnetic resonance experiments to measure methane diffusion in seven organic-rich shale samples from a Middle Eastern source rock. At $\sim 13.9 \mathrm{MPa}$ and ambient temperature, the methane diffusion coefficient was found to be $\sim 2 \div 6 \times 10^{-9} \mathrm{~m}^{2} / \mathrm{s}$, comparable to the results obtained here.

For isothermal mass transfer of pure species through a porous medium, transport diffusivity is generally greater than selfdiffusivity, because interparticle correlations affect collective diffusivity, positively contributing to transport. ${ }^{39}$ Our results differ from this general trend, because the transport diffusivity of all gases considered is slower than the corresponding selfdiffusivity. This unexpected result is probably due to molecular clustering. Molecular clustering within pores is often ascribed to hydrogen bonding. ${ }^{40} \mathrm{~A}$ recent experimental study provided evidence that the $\mathrm{H}_{2} \mathrm{~S}$ dimer has an anisotropic structure exhibiting one $\mathrm{S}-\mathrm{H} \cdots \mathrm{S}$ hydrogen bond $(\mathrm{HB}){ }^{41}$ In addition, the interactions between benzene and $\mathrm{H}_{2} \mathrm{~S}$ are due to $\mathrm{SH}-\pi$ interactions, a type of $\mathrm{HB}$ abundant in biological systems. ${ }^{42}$ Preferential interactions between benzene and $\mathrm{CO}_{2}$ (ref 30) could lead to clustering. Indeed, the surface density distributions for $\mathrm{H}_{2} \mathrm{~S}$ and $\mathrm{CO}_{2}$ within various layers inside the crowded nanopore (Figure S8) provide conclusive proof of the existence of molecular clusters in our systems. These clusters appear to be more pronounced in the presence of $\mathrm{H}_{2} \mathrm{~S}$ rather than $\mathrm{CO}_{2}$.

Although the value for the transport diffusivity of $\mathrm{CO}_{2}\left(/ \mathrm{H}_{2} \mathrm{~S}\right)$ should approach the corresponding self-diffusivity, $D_{s}$, at low mole fraction, we observe a small deviation between $D_{\mathrm{t}}$ and $D_{\mathrm{s}}$ at $x_{\mathrm{CO}_{2} / \mathrm{H}_{2} \mathrm{~S}} \rightarrow 0$. This discrepancy is ascribed to uncertainties in the calculation of self-diffusivity using the Green-Kubo method, which is based on the integration of velocity-velocity autocorrelation functions over infinite times. ${ }^{43}$ 

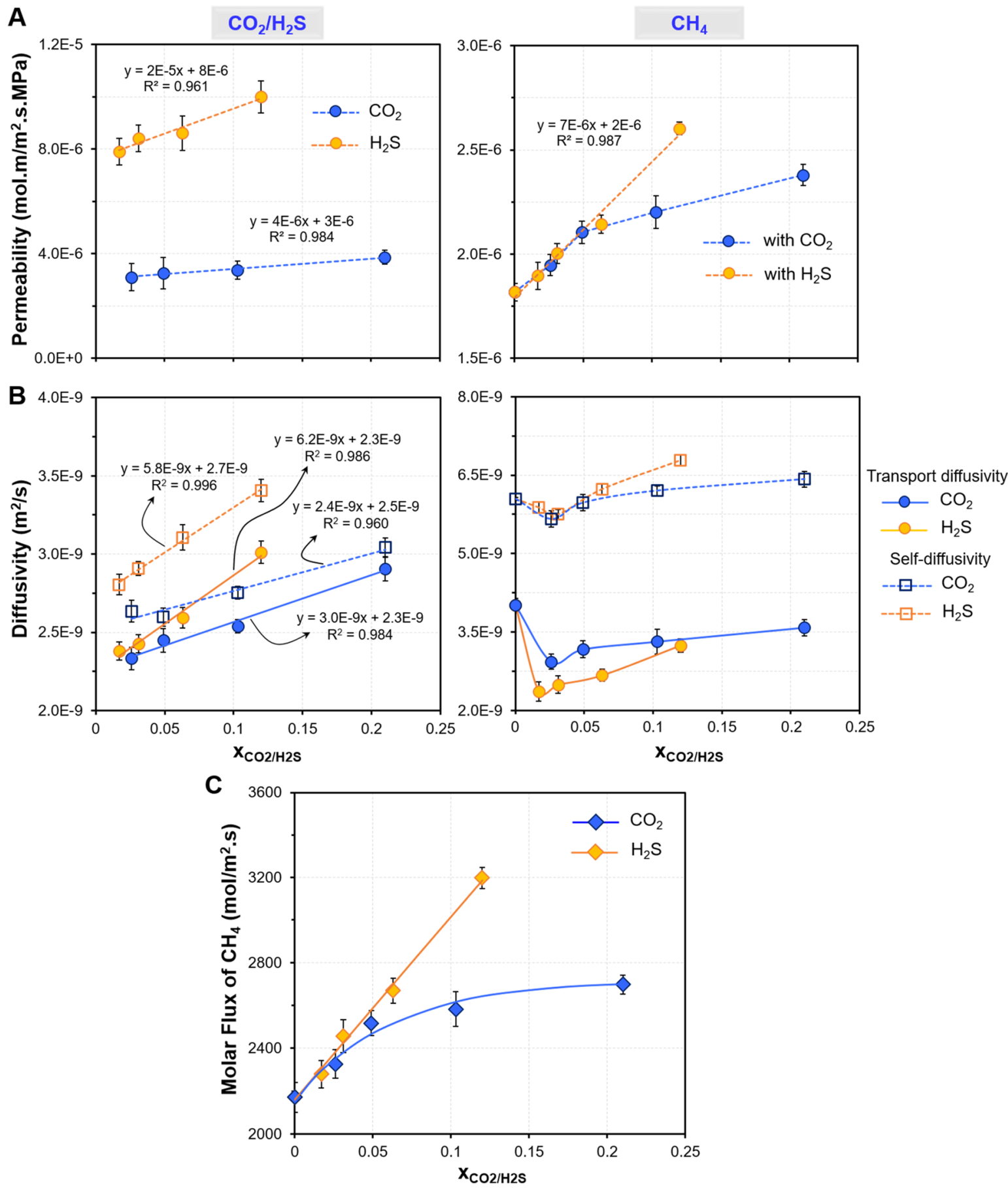

Figure 3. (A) Permeability and (B) transport diffusivity as determined by boundary driven nonequilibrium MD simulations across the benzene-filled pore for $\mathrm{CO}_{2}$ and $\mathrm{H}_{2} \mathrm{~S}$ (blue and yellow closed symbols in the left panels, respectively) and $\mathrm{CH}_{4}$ (right panels) for the various systems considered. Selfdiffusivity data (open symbols), as determined by the Green-Kubo formulation, are also reported for $\mathrm{CO}_{2} / \mathrm{H}_{2} \mathrm{~S}$ and $\mathrm{CH}_{4}$ in panel B. (C) Molar flux of methane in $\mathrm{CO}_{2}-\mathrm{CH}_{4}$ (blue) and $\mathrm{H}_{2} \mathrm{~S}-\mathrm{CH}_{4}$ (yellow) mixtures across the benzene-filled $\mathrm{SiO}_{2}$ nanopore as a function of $\mathrm{CO}_{2} / \mathrm{H}_{2} \mathrm{~S}$ bulk mole fraction.

Although the transport diffusivity of $\mathrm{CH}_{4}$ in the presence of either $\mathrm{CO}_{2}$ or $\mathrm{H}_{2} \mathrm{~S}$ is slower than that for pure $\mathrm{CH}_{4}$ (Figure $3 \mathrm{~B}$, right panel), we observe an increase of $\mathrm{CH}_{4}$ molar flux when loading $\mathrm{CO}_{2}$ or $\mathrm{H}_{2} \mathrm{~S}$ (Figure $3 \mathrm{C}$ ). This confirms that $\mathrm{CO}_{2}$ and $\mathrm{H}_{2} \mathrm{~S}$ play the role of carriers, facilitating $\mathrm{CH}_{4}$ transport through the crowded nanopore. ${ }^{44,45}$ The facilitated transport factors are estimated to be $\sim 1.46$ and 1.77 , respectively.

For solute transport through pores filled with solvents (i.e., our crowded $\mathrm{SiO}_{2}$ pore), the local distribution of solvent molecules yields preferential transport pathways for the solute. $^{46,47}$ To better understand the transport behavior of $\mathrm{CO}_{2}, \mathrm{H}_{2} \mathrm{~S}$, and $\mathrm{CH}_{4}$, we quantified free-energy ( $\mathrm{FE}$ ) landscapes by implementing well-tempered metadynamics. ${ }^{48,49}$ The results for $\mathrm{CO}_{2}$ and $\mathrm{H}_{2} \mathrm{~S}$ (panels $\mathrm{A}$ and $\mathrm{B}$ of Figure 4, respectively), show that the path connecting neighboring $\mathrm{FE}$ wells for $\mathrm{CO}_{2}$ is longer and more tortuous than the one encountered by $\mathrm{H}_{2} \mathrm{~S}$. However, to traverse the pore, $\mathrm{H}_{2} \mathrm{~S}$ molecules can jump only from one FE well to another, across barriers of $\sim 9 \mathrm{kcal} / \mathrm{mol}$, whereas $\mathrm{CO}_{2}$ encounters barriers of only $\sim 6.4 \mathrm{kcal} / \mathrm{mol}{ }^{47}$ This suggests that the $\mathrm{CO}_{2}$ molecule can travel more easily, 

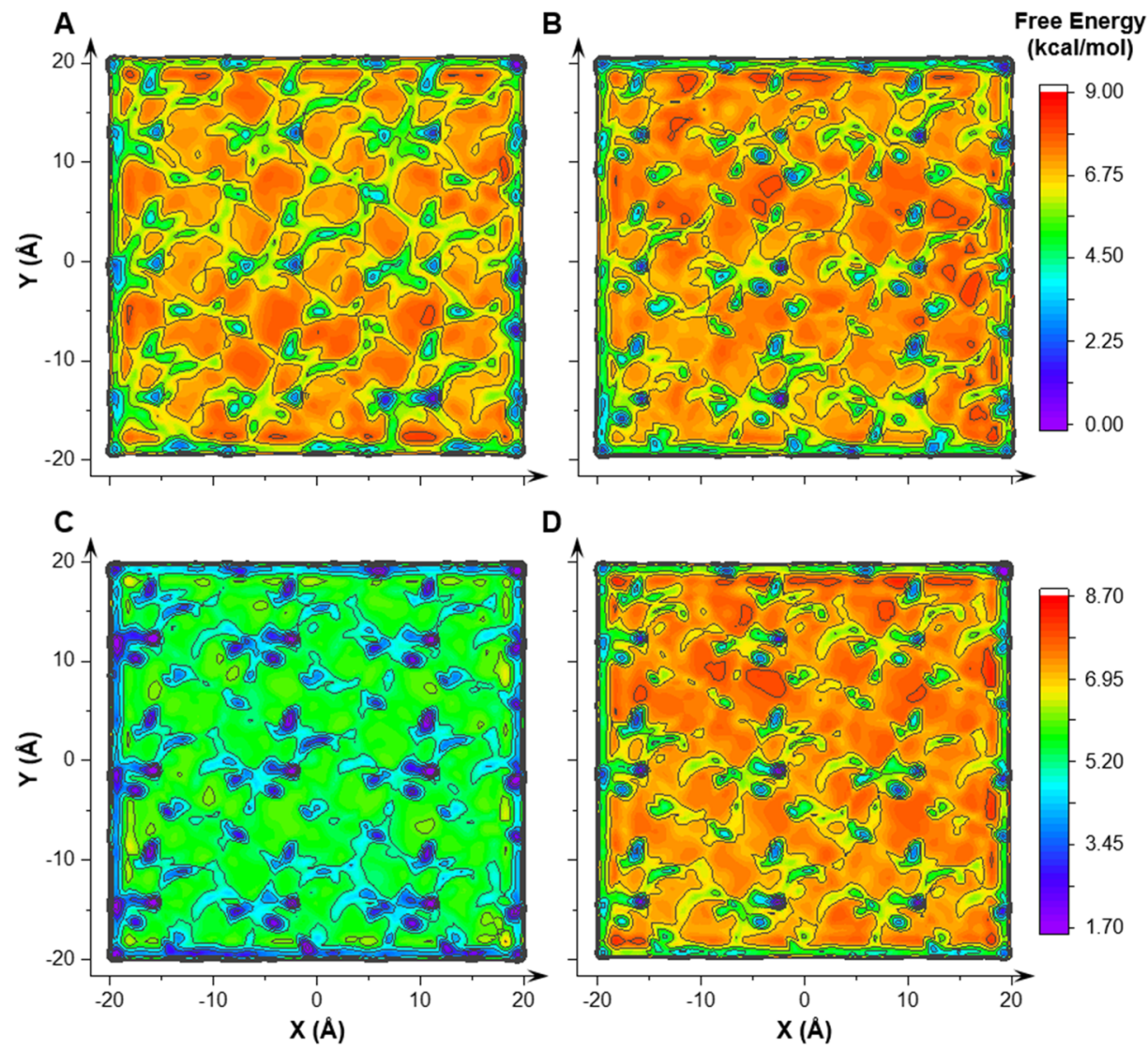

Figure 4. Free-energy landscapes projected onto planes parallel to the pore surface for one $\mathrm{CO}_{2}$ (panel A) and one $\mathrm{H}_{2} \mathrm{~S}$ (panel B) molecule traveling inside the crowded nanopore (system 0 , with composition shown in Table 1 and Figure $\mathrm{S} 1$ ), and that for one $\mathrm{CH}_{4}$ molecule moving inside the pore of system $1 \mathrm{C}$ (panel C) and $1 \mathrm{H}$ (panel D). The results are obtained from well-tempered metadynamics simulations. The collective variables chosen are the components of the distance along the three Cartesian coordinates $(x, y, z)$ between one molecule species $i$ and the center of the benzene-filled pore.

notwithstanding the more tortuous path, compared to $\mathrm{H}_{2} \mathrm{~S}$. In our systems, it appears that the longer path length that characterizes $\mathrm{CO}_{2}$ transport is balanced by the lower $\mathrm{FE}$ barriers, as the pore diffusivity of $\mathrm{CO}_{2}$ is similar to that for $\mathrm{H}_{2} \mathrm{~S}$ $\left(\sim 2.3 \times 10^{-9} \mathrm{~m}^{2} / \mathrm{s}\right)$ at $x_{\mathrm{CO}_{2} / \mathrm{H}_{2} \mathrm{~S}} \rightarrow 0$.

In Figure 4C,D we found similar patterns connecting FE wells as experienced by $\mathrm{CH}_{4}$ in systems $1 \mathrm{C}$ and $1 \mathrm{H}$ (in the presence of $\mathrm{CO}_{2}$ and $\mathrm{H}_{2} \mathrm{~S}$, respectively); however, in the presence of $\mathrm{CO}_{2}$, deep FE wells appear, within which $\mathrm{CH}_{4}$ molecules accumulate. Lower FE barriers are found in system 1C $(\sim 4.4 \mathrm{kcal} / \mathrm{mol})$ compared to those observed for system $1 \mathrm{H}(\sim 6.3 \mathrm{kcal} / \mathrm{mol})$, likely due to the benzene- $-\mathrm{CO}_{2}$ interactions, which are weaker than those between benzene and $\mathrm{H}_{2} \mathrm{~S}$. This difference in barriers seems to be correlated and potentially explains why the diffusivity of $\mathrm{CH}_{4}$ in the pore of system $1 \mathrm{C}\left(50 \mathrm{CO}_{2}-1080\right.$ $\left.\mathrm{CH}_{4}\right)$ is greater than that in system $1 \mathrm{H}\left(50 \mathrm{H}_{2} \mathrm{~S}-1090 \mathrm{CH}_{4}\right)$ (Figure 3B, right panel).

In conclusion, our simulations demonstrate that adding fluids such as $\mathrm{CO}_{2}$ or $\mathrm{H}_{2} \mathrm{~S}$ impacts significantly fluid transport mechanisms in organic-rich sedimentary rocks. Particularly, $\mathrm{CO}_{2} / \mathrm{H}_{2} \mathrm{~S}$ adsorption displaces and perhaps swells the organics, leading to noticeable differences for $\mathrm{CH}_{4}$ solubility in confinement. More importantly, $\mathrm{CO}_{2}$ and $\mathrm{H}_{2} \mathrm{~S}$ facilitate $\mathrm{CH}_{4}$ transport through organic-rich caprock pores, acting as mobile carriers. Our results emphasize the importance of fluid-fluid and fluidpore interactions, compounded by changes in the structure of confined fluids, in determining transport mechanisms of importance for geo-energy applications such as carbon sequestration in caprocks and enhanced hydrocarbon production and provide a general understanding of fluid transport in crowded pores frequently encountered in nature.

\section{ASSOCIATED CONTENT}

\section{SI Supporting Information}

The Supporting Information is available free of charge at https://pubs.acs.org/doi/10.1021/acs.jpclett.9b03751.

Details about simulation models, algorithms, implementation methods, calculation procedures and results for properties of interest such as density profiles, in-plane surface density distributions, adsorption isotherms, amount of benzene displaced, cross-sectional area, and solubility of all species $\left(\mathrm{CO}_{2}, \mathrm{H}_{2} \mathrm{~S}, \mathrm{CH}_{4}\right.$, and benzene) (PDF)

\section{AUTHOR INFORMATION}

\section{Corresponding Authors}

Anh Phan - Department of Chemical Engineering, University College London, London WC1E 7JE, U.K.;

Email: anh.phan.13@ucl.ac.uk

Alberto Striolo - Department of Chemical Engineering, University College London, London WC1E 7JE, U.K.; ○ orcid.org/0000-0001-6542-8065; Email: a.striolo@ ucl.ac.uk

Complete contact information is available at: https://pubs.acs.org/10.1021/acs.jpclett.9b03751 


\section{Notes}

The authors declare no competing financial interest.

\section{ACKNOWLEDGMENTS}

Generous allocations of computing time were provided by ARCHER, the UK National Supercomputing Service (http:// www.archer.ac.uk) via our membership in the UK's HEC Materials Chemistry Consortium, which is funded by EPSRC (EP/L000202, EP/R029431), the University College London Research Computing Platforms Support (Myriad), the Oklahoma Supercomputing Center for Education and Research (OSCER), and the National Energy Research Scientific Computing Center (NERSC) at Lawrence Berkeley National Laboratory. NERSC is supported by the DOE Office of Science under Contract No. DE-AC02-05CH11231. This work is supported, in part by the Science4CleanEnergy European research consortium funded by European Union's Horizon 2020 research and innovation programme, under Grant Agreement No. 764810 (S4CE). The Authors are grateful to Dr Matteo Salvalaglio of University College London for interesting discussions during the preparation of the manuscript.

\section{REFERENCES}

(1) Bourg, I. C.; Beckingham, L. E.; DePaolo, D. J. The Nanoscale Basis of $\mathrm{CO}_{2}$ Trapping for Geologic Storage. Environ. Sci. Technol. 2015, 49, 10265-10284.

(2) Mathias, S. A.; Gluyas, J. G.; Goldthorpe, W. H.; Mackay, E. J. Impact of Maximum Allowable Cost on $\mathrm{CO}_{2}$ Storage Capacity in Saline Formations. Environ. Sci. Technol. 2015, 49, 13510-13518.

(3) Yang, C. B.; Trevino, R. H.; Zhang, T. W.; Romanak, K. D.; Wallace, K.; Lu, J. M.; Mickler, P. J.; Hovorka, S. D. Regional Assessment of $\mathrm{CO}_{2}$-Solubility Trapping Potential: A Case Study of the Coastal and Offshore Texas Miocene Interval. Environ. Sci. Technol. 2014, 48, 8275-8282.

(4) IPCC. IPCC Special Report on Carbon Dioxide Capture and Storage; Cambridge University Press: Cambridge, U.K., 2005.

(5) Smit, B.; Reimer, J. R.; Oldenburg, C. M.; Bourg, I. C. Introduction to Carbon Capture and Sequestration; Imperial College Press: London, 2014.

(6) Bourg, I. C. Sealing Shales Versus Brittle Shales: A Sharp Threshold in the Material Properties and Energy Technology Uses of Fine-Grained Sedimentary Rocks. Environ. Sci. Technol. Lett. 2015, 2, 255-259.

(7) Horn River Basin Unconventional Shale Gas Play Atlas; BC Oil and Gas Commission; Fort Saint John, 2014.

(8) Weiland, R. H.; Hatcher, N. A. Overcome Challenges in Treating Shale Gases. Hydrocarb Process 2012, 91, 45-48.

(9) Cipolla, C. L.; Lolon, E. P.; Erdle, J. C.; Rubin, B. Reservoir Modeling in Shale-Gas Reservoirs. Spe Reserv Eval Eng. 2010, 13, 638653.

(10) Tilley, B.; McLellan, S.; Hiebert, S.; Quartero, B.; Veilleux, B.; Muehlenbachs, K. Gas Isotope Reversals in Fractured Gas Reservoirs of the Western Canadian Foothills: Mature Shale Gases in Disguise. AAPG Bull. 2011, 95, 1399-1422.

(11) Parker, M.; Buller, D.; Petre, E.; Dreher, D. H. Haynesville ShalePetrophysical Evaluation. In SPE Rocky Mountain Petroleum Technology Conference, Denver, CO, 2009; 122937.

(12) Pirzadeh, P.; Lesage, K. L.; Marriott, R. A. Hydraulic Fracturing Additives and the Delayed Onset of Hydrogen Sulfide in Shale Gas. Energy Fuels 2014, 28, 4993-5001.

(13) Maddox, R. N.; Morgan, J. Gas Treating and Sulfur Recovery. In Gas Conditioning and Processing; Campbell Petroleum Series: Norman, OK, 2006; Vol. 4.

(14) Snaebjornsdottir, S. O.; Oelkers, E. H.; Mesfin, K.; Aradottir, E. S.; Dideriksen, K.; Gunnarsson, I.; Gunnlaugsson, E.; Matter, J. M.; Stute, M.; Gislason, S. R. The Chemistry and Saturation States of Subsurface Fluids During the in Situ Mineralisation of $\mathrm{CO}_{2}$ and $\mathrm{H}_{2} \mathrm{~S}$ at the Carbfix Site in Sw-Iceland. Int. J. Greenhouse Gas Control 2017, 58, $87-102$.

(15) Hofmann, A.; van Strien, W.; Malekzadeh, R. Improving the Efficiency of $\mathrm{H}_{2} \mathrm{~S}$ Mitigation in Middle East Oil and Gas Fields. In $\mathrm{Abu}$ Dhabi International Petroleum Exhibition \& Conference; Society of Petroleum Engineers: Abu Dhabi, UAE, 2017.

(16) Khan, C.; Amin, R.; Madden, G. Effects of $\mathrm{CO}_{2}$ and Acid Gas Injection on Enhanced Gas Recovery and Storage. J. Pet. Explor. Prod. Technol. 2013, 3, 55-60.

(17) Falk, K.; Coasne, B.; Pellenq, R.; Ulm, F. J.; Bocquet, L. Subcontinuum Mass Transport of Condensed Hydrocarbons in Nanoporous Media. Nat. Commun. 2015, 6, 6949.

(18) Obliger, A.; Pellenq, R.; Ulm, F. J.; Coasne, B. Free Volume Theory of Hydrocarbon Mixture Transport in Nanoporous Materials. J. Phys. Chem. Lett. 2016, 7, 3712-3717.

(19) Apostolopoulou, M.; Dusterhoft, R.; Day, R.; Stamatakis, M.; Coppens, M.-O.; Striolo, A. Estimating Permeability in Shales and Other Heterogeneous Porous Media: Deterministic Vs. Stochastic Investigations. Int. J. Coal Geol. 2019, 205, 140-154.

(20) Phan, A.; Striolo, A. Methane Transport through Hierarchical Silica Micro-Mesoporous Materials: From Non-Equilibrium Atomistic Simulations to Phenomenological Correlations. Microporous Mesoporous Mater. 2019, 288, 109559.

(21) Rexer, T. F. T.; Benham, M. J.; Aplin, A. C.; Thomas, K. M. Methane Adsorption on Shale under Simulated Geological Temperature and Pressure Conditions. Energy Fuels 2013, 27, 3099-3109.

(22) Mosher, K.; He, J. J.; Liu, Y. Y.; Rupp, E.; Wilcox, J. Molecular Simulation of Methane Adsorption in Micro- and Mesoporous Carbons with Applications to Coal and Gas Shale Systems. Int. J. Coal Geol. 2013, 109, 36-44.

(23) Fischer, K.; Chen, J.; Petri, M.; Gmehling, J. Solubility of $\mathrm{H}_{2} \mathrm{~S}$ and $\mathrm{CO}_{2}$ in N-Octyl-2-Pyrrolidone and of $\mathrm{H}_{2} \mathrm{~S}$ in Methanol and Benzene. AIChE J. 2002, 48, 887-893.

(24) Lay, E. N.; Taghikhani, V.; Ghotbi, C. Measurement and Correlation of $\mathrm{CO}_{2}$ Solubility in the Systems of $\mathrm{CO}_{2}$ Plus Toluene, $\mathrm{CO}_{2}$ Plus Benzene, and $\mathrm{CO}_{2}$ Plus N-Hexane at near-Critical and Supercritical Conditions. J. Chem. Eng. Data 2006, 51, 2197-2200.

(25) Phan, A.; Cole, D. R.; Striolo, A. Aqueous Methane in Slit-Shaped Silica Nanopores: High Solubility and Traces of Hydrates. J. Phys. Chem. C 2014, 118, 4860-4868.

(26) Ho, L. N.; Schuurman, Y.; Farrusseng, D.; Coasne, B. Solubility of Gases in Water Confined in Nanoporous Materials: Zsm-5, Mcm-41, and Mil-100. J. Phys. Chem. C 2015, 119, 21547-21554.

(27) Badmos, S. B.; Striolo, A.; Cole, D. R. Aqueous Hydrogen Sulfide in Slit-Shaped Silica Nanopores: Confinement Effects on Solubility, Structural, and Dynamical Properties. J. Phys. Chem. C 2018, 122, 14744-14755.

(28) Plimpton, S. Fast Parallel Algorithms for Short-Range MolecularDynamics. J. Comput. Phys. 1995, 117, 1-19.

(29) Heinz, H. Computational Screening of Biomolecular Adsorption and Self-Assembly on Nanoscale Surfaces. J. Comput. Chem. 2009, 31, $1564-1568$

(30) Chen, L.; Cao, F. L.; Sun, H. Ab Initio Study of the Pi-Pi Interactions between $\mathrm{CO}_{2}$ and Benzene, Pyridine, and Pyrrole. Int. J. Quantum Chem. 2013, 113, 2261-2266.

(31) Ringer, A. L.; Figgs, M. S.; Sinnokrot, M. O.; Sherrill, C. D. Aliphatic C-H/Pi Interactions: Methane-Benzene, Methane-Phenol, and Methane-Indole Complexes. J. Phys. Chem. A 2006, 110, 1082210828.

(32) Sinnokrot, M. O.; Sherrill, C. D. Highly Accurate Coupled Cluster Potential Energy Curves for the Benzene Dimer: Sandwich, TShaped, and Parallel-Displaced Configurations. J. Phys. Chem. A 2004, 108, 10200-10207.

(33) Sherrill, C. D.; Takatani, T.; Hohenstein, E. G. An Assessment of Theoretical Methods for Nonbonded Interactions: Comparison to Complete Basis Set Limit Coupled-Cluster Potential Energy Curves for the Benzene Dimer, the Methane Dimer, Benzene-Methane, and Benzene- $\mathrm{H}_{2} \mathrm{~S}$. J. Phys. Chem. A 2009, 113, 10146-10159. 
(34) Hill, R. J.; Jarvie, D. M.; Zumberge, J.; Henry, M.; Pollastro, R. M. Oil and Gas Geochemistry and Petroleum Systems of the Fort Worth Basin. AAPG Bull. 2007, 91, 445-473.

(35) Martini, A. M.; Walter, L. M.; McIntosh, J. C. Identification of Microbial and Thermogenic Gas Components from Upper Devonian Black Shale Cores, Illinois and Michigan Basins. AAPG Bull. 2008, 92, 327-339.

(36) Liu, J.; Jiang, J. W. Molecular Design of Microporous Polymer Membranes for the Upgrading of Natural Gas. J. Phys. Chem. C 2019, 123, 6607-6615.

(37) Dubbeldam, D.; Ford, D. C.; Ellis, D. E.; Snurr, R. Q. A New Perspective on the Order-N Algorithm for Computing Correlation Functions. Mol. Simul. 2009, 35, 1084-1097.

(38) An, Y.; Althaus, S. M.; Liu, H. H.; Chen, J. H. Nuclear Magnetic Resonance Measurement of Methane Diffusion in Organic-Rich Shales. Fuel 2019, 247, 160-163.

(39) Smit, B.; Maesen, T. L. M. Molecular Simulations of Zeolites: Adsorption, Diffusion, and Shape Selectivity. Chem. Rev. 2008, 108, $4125-4184$.

(40) Krishna, R. Diffusion in Porous Crystalline Materials. Chem. Soc. Rev. 2012, 41, 3099-3118.

(41) Das, A.; Mandal, P. K.; Lovas, F. J.; Medcraft, C.; Walker, N. R.; Arunan, E. The $\mathrm{H}_{2} \mathrm{~S}$ Dimer Is Hydrogen-Bonded: Direct Confirmation from Microwave Spectroscopy. Angew. Chem., Int. Ed. 2018, 57, 15199-15203.

(42) Alberti, M.; Aguilar, A.; Huarte-Larranaga, F.; Lucas, J. M.; Pirani, F. Benzene-Hydrogen Bond $\left(\mathrm{C}_{6} \mathrm{H}_{6}-\mathrm{HX}\right)$ Interactions: The Influence of the $\mathrm{X}$ Nature on Their Strength and Anisotropy. J. Phys. Chem. A 2014, 118, 1651-1662.

(43) Oliveira, L. D.; Greaney, P. A. Method to Manage Integration Error in the Green-Kubo Method. Phys. Rev. E: Stat. Phys., Plasmas, Fluids, Relat. Interdiscip. Top. 2017, 95, 023308.

(44) Li, Y. F.; Wang, S. F.; He, G. W.; Wu, H.; Pan, F. S.; Jiang, Z. Y. Facilitated Transport of Small Molecules and Ions for Energy-Efficient Membranes. Chem. Soc. Rev. 2015, 44, 103-118.

(45) Wang, J. T.; Wang, S. F.; Xin, Q. P.; Li, Y. F. Perspectives on Water-Facilitated $\mathrm{CO}_{2}$ Capture Materials. J. Mater. Chem. A 2017, 5, 6794-6816.

(46) Phan, A.; Cole, D. R.; Weiss, R. G.; Dzubiella, J.; Striolo, A. Confined Water Determines Transport Properties of Guest Molecules in Narrow Pores. ACS Nano 2016, 10, 7646-7656.

(47) Bui, T.; Phan, A.; Cole, D. R.; Striolo, A. Transport Mechanism of Guest Methane in Water-Filled Nanopores. J. Phys. Chem. C 2017, 121, $15675-15686$.

(48) Barducci, A.; Bussi, G.; Parrinello, M. Well-Tempered Metadynamics: A Smoothly Converging and Tunable Free-Energy Method. Phys. Rev. Lett. 2008, 100, 020603.

(49) Bonomi, M.; Branduardi, D.; Bussi, G.; Camilloni, C.; Provasi, D.; Raiteri, P.; Donadio, D.; Marinelli, F.; Pietrucci, F.; Broglia, R. A.; Parrinello, M. Plumed: A Portable Plugin for Free-Energy Calculations with Molecular Dynamics. Comput. Phys. Commun. 2009, 180, 19611972. 